\title{
Mountain roads shift native and non-native plant species ranges
}

Jonas J. Lembrechts ${ }^{1}$, Jake M. Alexander², Lohengrin A. Cavieres ${ }^{3}$, Sylvia Haider ${ }^{4}, 5$, Jonathan Lenoir ${ }^{6}$, Christoph Kueffer?', Keith McDougall, Bridgett J. Naylor ${ }^{8}$, Martín A. Nuñez', Aníbal Pauchard ${ }^{3}$, Lisa J. Rew ${ }^{10}$, Ivan Nijs' ${ }^{1}$, Ann Milbau ${ }^{11,12}$

${ }^{1}$ Centre of Excellence of Plant and Vegetation Ecology, University of Antwerp, 2610 Wilrijk, Belgium ${ }^{2}$ Institute of Integrative Biology, Department of Environmental Systems Science, ETH Zürich, CH8092 Zürich, Switzerland

${ }^{3}$ Laboratorio de Invasiones Biológicas, Universidad de Concepción and Institute of Ecology and Biodiversity (IEB), Casilla 160-C, Concepción, Chile

${ }^{4}$ Institute of Biology / Geobotany and Botanical Garden, Martin Luther University Halle-Wittenberg, Halle (Saale), Germany,

${ }^{5}$ German Centre for Integrative Biodiversity Research (iDiv), Leipzig, Germany

${ }^{6}$ UR “Ecologie et Dynamique des Systèmes Anthropisés” (EDYSAN, FRE 3498 CNRS-UPJV), Université de Picardie Jules Verne, 1 Rue des Louvels, 80000 Amiens, France

${ }^{7}$ Department of Ecology, Environment and Evolution, La Trobe University, PO Box 821, Wodonga, Victoria, 3689, Australia

${ }^{8}$ USDA Forest Service, Pacific Northwest Research Station, La Grande, OR 97850, United States of America

${ }^{9}$ Grupo de Ecología de Invasiones, Universidad Nacional del Comahue, INIBIOMA, CONICET, Quintral 1250, C.P. 8400, Bariloche, Argentina

${ }^{10}$ Department of Land Resources and Environmental Sciences, Montana State University, Bozeman, MT 59717, United States of America

${ }^{11}$ Climate Impacts Research Centre (CIRC), Department of Ecology and Environmental Science, Umeå University, SE-981 07 Abisko, Sweden

${ }^{12}$ Research Institute for Nature and Forest INBO, Department of Biodiversity and Natural Environment, 1070 Brussels, Belgium

Corresponding author: Jonas J. Lembrechts, Centre of Excellence of Plant and Vegetation Ecology, University of Antwerp, 2610 Wilrijk, Belgium. E-mail: jonas.lembrechts@uantwerpen.be

Decision date: $19-$ Feb-2016

This article has been accepted for publication and undergone full peer review but has not been through the copyediting, typesetting, pagination and proofreading process, which may lead to differences between this version and the Version of Record. Please cite this article as doi: [10.1111/ecog.02200].

'This article is protected by copyright. All rights reserved.' 


\section{Abstract}

Roads are known to act as corridors for dispersal of plant species. With their variable microclimate, role as corridors for species movement and reoccurring disturbance events, they show several characteristics that might influence range dynamics of both native and non-native species. Previous research on plant species ranges in mountains however seldom included the effects of roads. To study how ranges of native and non-native species differ between roads and adjacent vegetation, we used a global dataset of plant species composition along mountain roads. We compared average elevation and range width of species, and used GLMMs to compile their range optimum and amplitude. We then explored differences between roadside and adjacent plots based on a species' origin (native vs. nonnative) and nitrogen and temperature affinity.

Most non-native species had on average higher elevational ranges and broader amplitudes in roadsides. Higher optima for non-native species were associated with high nitrogen and temperature affinity. While native species with a lowland origin showed patterns comparable to those in non-native species, native species from high elevations had significantly lower elevational ranges in roadsides compared to the adjacent vegetation.

We conclude that roadsides indeed change the elevational ranges of a variety of species.These changes are not limited to the expansion of non-native species along mountain roads, but also include both upward and downward changes in ranges of native species. Roadsides may thus facilitate upward range shifts, for instance related to climate change, and they could serve as corridors to facilitate migration of alpine species between adjacent high-elevation areas. We recommend including the effects of mountain roads in species distribution models to fine-tune the predictions of range changes in a warming climate.

Keywords: Disturbance, mountain roads, native and non-native species, nitrogen and temperature affinity, plant invasion, range shifts, species distributions. 


\section{Introduction}

Mountain roads provide an important anthropogenic impact on global mountain ecosystems by causing reoccurring disturbances, changing species compositions, fragmenting habitats, changing the hydrology, soil ecology and nutrient availability, altering the microclimate, and funneling anthropogenic effects into the most pristine environments (Forman and Alexander 1998, Forman et al. 2003, Müllerová et al. 2011). In addition, roads might contribute to responses of vegetation to global change, especially in mountains, where roads span steep climate gradients over short distances and thus interact with sudden changes in environmental conditions (Pauchard et al. 2009). Thorough knowledge of the effects of mountain roads on plant elevational ranges will be important for mountain conservation in a future with a rapidly changing climate and increased anthropogenic presence in mountains.

Previous research on plant species ranges in mountains have seldom included the effects of roads or, if they did, focused on either native or non-native species or only studied general patterns of species richness and composition. For non-native species, a general trend of upward movement in mountains has been documented over time (Pyšek et al. 2011), and in most regions, non-native species show a consistent pattern of declining abundance with elevation (Becker et al. 2005, Haider et al. 2010, Alexander et al. 2011, Haider et al. 2011, Juvik et al. 2011). Non-native species populations indeed seem to establish first in the lowlands and invade mountains from there, using roads as their main vector (Haider et al. 2010, Alexander et al. 2011, McDougall et al. 2011). The function of roads as corridors for non-native species has also been reported several times in other ecosystems (Gelbard and Belnap 2003, Pauchard et al. 2009, Pollnac et al. 2012). Invasion away from roadsides into the adjacent mountain vegetation has until now been limited (Leung et al. 2009, Alexander et al. 2011, Lembrechts et al. 2014, Pollnac and Rew 2014, Seipel et al. 2015), which suggests that disturbance might at this time be a more important explanatory variable than climate to 
explain the observed patterns of non-native species distributions in mountains (Marini et al. 2012).

The effect of roads on native species' elevational ranges is poorly documented. Knowledge of range changes of native terrestrial plants in mountain ecosystems is mostly limited to observations of temporal upward range shifts in the light of contemporary climate change, unrelated to roads (Grabherr et al. 1994, Walther et al. 2002, Pauli et al. 2007, Lenoir et al. 2008, Felde et al. 2012). Several studies warn of rapid area loss for endemic high-elevation species (Pauli et al. 2007, Jump et al. 2012), and a failure of lower elevation species to migrate upwards to track climate change (Bertrand et al. 2011, Corlett and Westcott 2013). Recently, Lenoir et al. (2010) suggested that unexpected downward shifts of species' lower elevational range limits (cf. the trailing edge) may be caused by complex interactions between climate change and increased disturbance levels. Knowledge of native species' distributions in mountain roadsides is fragmented and generally limited to patterns of species richness (Paiaro et al. 2011, Lembrechts et al. 2014). A recent study in the northern Scandes showed that at lower elevations, mostly competitive and ruderal species benefit from roadside conditions, while in the alpine zone roadsides are mainly occupied by stresstolerant species (Lembrechts et al. 2014). Paiaro et al. (2011) suggested that roadsides may function as plant species corridors both in upward and downward directions.

Roads combine several features that could potentially explain changes in plant species ranges in the ecosystems they cross. They host a more variable and extreme microclimate than the surrounding vegetation, affect soil hydrology, and improve nutrient availability through the addition of dissolved nutrients and volatile nitrogen oxides, and through an increase in soil pH (Forman et al. 2003, Johnston and Johnston 2004, Delgado et al. 2007, Müllerová et al. 2011). The role of vehicles and hikers as vectors for travelling species and the related increased propagule pressure along roads can also explain changes in the 
distribution of plant species (Forman and Alexander 1998, Forman et al. 2003, Ansong and Pickering 2013). Finally, roadsides are disturbed environments (Forman et al. 2003), characterized by repeated set-backs of succession to earlier stages (Güsewell and Klötzli 2012) and they consequently have reduced levels of competition (Forman et al. 2003). These lower levels of competition along roads might influence species distributions by allowing species to increase their realised niche width (Bolnick et al. 2010). Based on these features and the known higher alpha diversity of plant species in roadsides (Avon et al. 2010, Paiaro et al. 2011, Bergès et al. 2013, Lembrechts et al. 2014), an expansion of plant elevational ranges in roadsides compared to the surrounding vegetation can be expected in mountains. However, the sizes and directions of such shifts likely depend on species-specific characteristics, as different species will profit or suffer differently from the altered environment in roadsides.

In this paper we compare differences in the elevational range of species in roadsides and the adjacent vegetation. Understanding the effects of mountain roads on species' elevational ranges is not only important from a theoretical point of view, but also crucial to improve species distribution models to forecast future climate change impacts on mountain biota and to decide on informed management strategies for mountain ecosystems. We used a dataset based on a large-scale monitoring effort of plant species distributions along roadsides and within adjacent natural vegetation across elevation gradients in eight mountain regions (MIREN 2005), and applied two different modelling approaches to study general and species-specific range patterns. The observed patterns were then analysed for effects of a species' origin (native or non-native) and temperature and nitrogen affinity (Landolt 2010). We hypothesized that (1) elevational ranges are in general broader in roadsides than in the adjacent natural vegetation, (2) the difference in range amplitude between roadsides and adjacent plots will be more positive for non-native than for native species and (3), the magnitude and direction of differences for both native and non-native 
species will depend on a species' ecological characteristics, with higher optima in roadsides compared to the adjacent plots for lowland nutrient- and temperature-loving species, but lower optima for highland species with opposite affinities.

\section{Materials and methods}

\section{Survey design}

Vegetation surveys were performed during the summer of 2012 (2014 in AR) in eight regions within MIREN (the Mountain Invasion Research Network) (MIREN 2005, McDougall et al. 2011, Kueffer et al. 2014): the Andes in Argentina (AR), the Alps in Australia (AU), the Andes in Central Chile (CLC), Greater Yellowstone Ecosystem in Montana, USA (MT), the Northern Scandes in Norway (NO) and the Blue Mountains in Oregon, USA (OR), the Andes in Southern Chile (CLS), the Alps in Switzerland (SW), see Table 1.

In each region, three roads were selected (four in SW, one in CLC) that extended over a broad elevation gradient (spanning 618 to 1715 elevational meters depending on the region) and were open to vehicular traffic for at least part of the year. The lowest sampling point of a road was the point below which there was no substantial change in elevation anymore, the highest sampling point depended on regional constraints, such as roads ending, merging or substantially changing in character. The elevational range covered by each road was divided into 19 equally spaced elevational bands (20 in SW, 15 in CLC), giving 20 (21 in SW, 16 in CLC) sampling sites per road.

At each sampling site, two $2 \times 50 \mathrm{~m}^{2}$ rectangular plots were laid out, with one plot parallel to the road (hereafter called 'roadside') and the other perpendicular to the centre of the first, with its midpoint 75 $\mathrm{m}$ away from the roadside and thus ranging from 50 to $100 \mathrm{~m}$ from the roadside (hereafter called 'adjacent plot'). In all plots, occurrence (presence/absence) of all vascular plant species was recorded.

\section{Elevational range differences between roadsides and adjacent plots}

Ranges based on the elevation of occurrence of species were calculated separately for roadsides and adjacent plots. Although elevation differences might not have exactly the same ecological meaning in different study regions, e.g. because of regional differences in adiabatic lapse rates and precipitation gradients, elevation currently is the best available variable to study range shifts in mountains. The use of climatic data would explain shifts in a more ecological way, but the current scale of globally available climatic datasets is too coarse $\left(\sim 1 \mathrm{~km}^{2}\right)$ to explain differences in elevational ranges on a scale 
of tens to hundreds of elevational meters in the mountains. Moreover, roadside-induced elevational range changes might not be a pure climatological effect, as other factors, such as disturbance and changes in nutrient levels, are likely to play an important role.

To assess elevational ranges in roadsides and adjacent plots we calculated range optima and amplitudes for every species with at least ten occurrences per region, with a minimum of five in both roadsides and adjacent plots. The range optimum is defined as the average elevation of occurrence, or the top of the species' occurrence curve, while the amplitude specifies the whole elevational range along which the species was observed (= range width). Differences in these values between roadsides and adjacent plots were calculated with two complementary approaches, of which the first one was coarse, allowing the use of a large species set and resulting in general and region-specific conclusions, while the second one was more detailed and precise, resulting in an ecologically meaningfull grouping of a limited set of species based on the location of their optimum along the elevational gradient.

In the first approach, average, minimum and maximum values of each species' elevational range in the roadside and the adjacent plots were calculated per region (pooling all roads in a given region), hereafter called "dataset A1" ( $\mathrm{N}=510$ region-specific values, for 438 different species, Supplementary material Appendix 1 Table. A1). The difference between a species' elevational occurrence optima was defined as the difference between its average elevation of occurrence in the roadside and in the adjacent plots. This resulted in positive values for species with a higher optimum in roadsides than in the adjacent plots, and vice versa. Differences between range amplitudes were defined as difference between ranges from maximum to minimum elevation of occurrence in roadside plots and adjacent plots.

For the second approach, we compiled species- and region-specific generalised linear mixed models (GLMMs). Species presence/absence per plot was modelled with a binomial distribution, as a function of elevation and with or without an interaction term for distance to the road (roadside/adjacent). We distinguished between species with a second degree (quadratic) and first degree (linear) binomial distribution. The former indicated a range optimum along the gradient (negative quadratic function with optimum within the sampled range, “dataset A2", see Supplementary material Appendix A Table A2), the latter a linear distribution, for which the range optimum lay above or below the gradient (positive or negative linear functions, monotonically increasing or decreasing along the sampled gradient, "dataset A3", see Supplementary material Appendix A Table A3). We 
acknowledged possible differences between roads within a region by adding "road" as a random factor. Models were fitted in $\mathrm{R}$ with the function glmer from the package lme4 (Bates et al. 2013). The function aictab from the package AICcmodavg (Mazerolle 2015) was used to select the model with the best fit based on the lowest AIC value. For details on the used models and coefficients, see Supplementary material Appendix 2.

There were 171 species for which the model with the best fit was a second degree function of elevation (dataset A2), of which 112 had next to this quadratic term a significant interaction between the linear elevation term and distance to the road, and 59 had an additional interaction between the quadratic elevation term and distance, hence showing a change in both optimum and amplitude (dataset A2, Supplementary material Appendix 1 Table A2). The difference between species optima was defined as the difference in elevational positions of the optimum information criteria (OPT) for roadside and adjacent plots (ter Braak and Looman 1986, Lenoir et al. 2008), calculated based on the coefficients from the GLMMs. Differences in range amplitudes were calculated by taking the difference between the GLMM's tolerance information criteria (AMP) (ter Braak and Looman 1986, Lenoir et al. 2008, see Supplementary material Appendix 2 for detailed calculations). Only those species that had an optimum elevation within the elevational range of the dataset were withhold.

For 44 species, the model with the best fit included only the linear elevation term, and a significant interaction between elevation and distance (dataset A3, see Supplementary material Appendix 1 Table A3). In these cases, the range edge (EDG) was defined as the inflection point of the model, and shifts in range edge between roadside and adjacent plots were examined (see Supplementary material Appendix 2 for calculations).

\section{Species origin and traits}

All species were marked as native or non-native for every region in which they occurred, based on data available from the MIREN-network. Any species introduced after AD 1500 within a given region was considered as non-native $\left(\mathrm{N}_{\text {non-native }}=99\right)$.

To verify if changes in species ranges between roadsides and adjacent plots can be explained by differences in species' affinity for temperature or nitrogen, we used indicator values for temperature and nitrogen from the Flora Indicativa, available for a set of 184 unique species (Table 1, Landolt 2010). Landolt indicator values range from one to five and characterize the average air temperature during the growing period of the species ("temperature") and a species preference for soil fertility 
("nitrogen"), with a value of one in both cases meaning a low affinity for the considered factor, and five a high affinity.

Landolt values were available for $85 \%$ of the species from the European regions (NO and SW), for 94 $\%$ of the non-native species in all regions, and for $18 \%$ of North-American native species (OR and MT) (Table 1). For native species from the southern hemisphere, Landolt value availability was limited (on average $6 \%$ ). This implies that our analyses based on the Landolt values will be biased towards regions with higher data availability. This bias does however not occur for non-native species and is limited to native species from the southern hemisphere. The European regions (NO and SW) had no non-native species with more than ten occurrences; the South-American datasets (AR, CLC, CLS) contained fewer native species than the other regions.

Data for species origin and traits were added to each dataset in the Appendix and datasets were grouped based on the species' origin (see Supplementary material Appendix 1 Table A1, A2 and A3).

\section{Statistical analysis}

Data from all three datasets (A1, A2, A3) were further tested with linear mixed models (LMMs) with species nested in region as a random factor (package nlme (Pinheiro et al. 2013)). First, a null model without any fixed effects was used, to test if the average optimum and amplitude (from datasets A1 and A2) differed from zero. Similar linear null models were used to analyse region-specific patterns by testing each regional dataset separately. These models were recreated for native and non-native species separately.

Next, LMMs with optimum, amplitude or edge as response variables, and species origin, species nitrogen and temperature affinity and their interactions as explanatory variables were used to explore correlations for all datasets, again with species nested in region as a random factor. For dataset A3, the location of the optimum (based on the slope of the linear curve with a positive slope indicating an optimum above the road fragment, and vice versa) was added as an extra fixed factor. Model simplification was done based on the lowest AIC value and significance of variables, and only the models with the best fit are shown.

A correlation test was used to test consistency in species patterns between regions, both with the differences in optima and in range amplitudes. The same test was used to analyse the correlation between differences in optima and amplitudes and the difference in amount of occurrences between

'This article is protected by copyright. All rights reserved.' 
roadsides and adjacent plots, and to test the relation between regional patterns for native species and the average nutrient affinity of a region's native species pool.

All data manipulations and analyses were performed in R (R Core Team 2013).

\section{Results}

\section{General patterns}

There was no general significant difference in species' elevation optima or amplitudes between roadsides and adjacent plots (LMMs, dataset $\mathrm{A} 1, \mathrm{df}=502$, optimum $P=0.564$, amplitude $P=0.373$ ). Range amplitudes of non-native species in dataset A1 were however on average 192 elevational meters broader in the roadsides than in the adjacent plots (Fig. 1, Table 2, right), which contrasted with the observations for native species, for which no general trends could be observed (Table 2, Fig. 1A, C).

In dataset A2, differences in optima and amplitudes for non-native species with optima along the studied road fragment were not significant (Fig. 1C, LMM, df $=39$ (31 species), optimum: $P=0.579$, amplitude: $P=0.538$, but the results from dataset A1 were supported by the regional trends (Fig. 1B and 1D, Table 2). Indeed, for four out of the eight regions (AU, CLS, OR and MT) we observed broader range amplitudes for non-native species in the roadsides in dataset A1. In OR and MT also, the optima were higher in the roadsides, but they were lower in AU and not significant in CLS. Moreover, in dataset A2, the one region (MT) with significant trends in non-native species showed on average higher optima in the roadsides than the adjacent plots (Fig. 1D).

Native species on the other hand showed on a regional basis a trend towards lower optima in roadsides, a trend significant in three regions (dataset A1; AU, SW, NO; Fig. 1B, Table 2). In two regions, a smaller amplitude was recorded (AR, AU) and in SW the amplitude was broader in roadsides than adjacent plots. In dataset A2, patterns for native species were marginally significant for AU (smaller amplitude), SW (broader amplitude) and OR (higher optimum).

\section{Location of optimum along the gradient}

Species were classified based on the location of their elevational optimum by integration of dataset A2 and A3 to unravel trends in range differences based on a species' location of origin that stay hidden in the general trends discussed before.

The strongest range differences were observed for non-native species with an optimum below the sampled road fragments (Fig. 2, "lowland species"). For these species, their upper range edge occured at higher elevations in the roadsides than in the adjacent plots $(\mathrm{LMM}$, Estimate $=677.1, P=0.021)$. 
Non-native species with optima along the sampled road fragments, on the other hand, did not show a significant response (see also Fig. 1C), and non-native species with an optimum above the sampled road fragment were not observed.

In native species, we observed different patterns for the three species groups: native species with their optimum below the sampled road fragment had upper edges at higher elevations in roadsides than adjacent plots and native species with an optimum along the sampled road fragment did not show any response. The lower range edges of native species with a range optimum above the sampled road fragments ("highland species"), on the other hand reached to lower elevations in the roadsides than the adjacent plots $(\mathrm{LMM}$, Highland $=-299.0$, Lowland $=472.5, P=0.002)$. An example of species with optimum along the roads (quadratic model) and below the sampled road fragment (linear model) can be seen respectively in Figures 2C and 2D.

\section{Temperature and nitrogen affinity}

Next to species origin (native or non-native), species' affinity for temperature and nitrogen also influenced how species ranges were affected by the presence of roads (Fig. 3, Table 3). In non-native species of European origin (94\% of the 71 non-native species in dataset A1 and $92 \%$ of the 37 nonnative species in dataset A2), high nitrogen affinity was correlated to higher range optima in the roadside than in the adjacent plots, while low nitrogen affinity resulted in lower range optima (Fig. 3A and $3 \mathrm{C}$ ). For the larger dataset $\mathrm{A} 1$, an additional trend related to temperature affinity was observed, with the highest difference in optima between roadsides and adjacent plots for non-native species with high indicator values for both nitrogen and temperature (upper right corner). It is however noteworthy that non-native species with temperature affinities below 3 were not observed, so almost no non-native species with lower roadside optima were recorded. In dataset A2, only the correlation with nitrogen remained (Fig. 3C, LMM: Optima $~ 1.78 * \mathrm{OR}_{\mathrm{N}(P=0.06)}+0.61 * \mathrm{~N}_{(P=0.01)}-0.55 * \mathrm{OR}_{\mathrm{N}} * \mathrm{~N}_{(P=0.06)}-1.90(P$ $=0.02)$. Non-native species with lower temperature affinity tended to have broader range amplitudes than the more thermophilic non-natives (borderline significant in Table 3 for dataset A1). Range amplitudes did not correlate significantly with nitrogen affinity.

Range optima of native species of European origin ( $48 \%$ of the the 439 native species in dataset A1 and $38 \%$ of the 125 native species in dataset A2) showed the same correlation with nitrogen as those from non-natives (Fig. 3B and 3D), with higher roadside optima for species with a high nitrogen affinity and vice versa, as there was no significant interaction between species origin and nitrogen 
(Table 3). The significant interaction of species origin with temperature affinity in dataset A1 resulted in lower optima for native species with a higher temperature affinity. In dataset 2 , again a positive correlation of optima with nitrogen affinity could be observed, but it was less stronge than in nonnative species (Fig. 3D, model see previous paragraph). Range amplitudes for native species were on average always broader in roadsides. Patterns for temperature and nitrogen affinity in dataset A3 were not significant and are not shown.

Regional models supported the abovementioned patterns (Table 3), although regional datasets were seldom large enough to allow the same model complexity. Differences in optima for native species were smaller than those for non-natives in MT and OR and showed a positive correlation with nitrogen affinity in SW. Differences in amplitudes were also larger for non-natives in AU, MT and OR, while the observed positive correlations with temperature affinity could also be observed in AU, CLS and SW. The regional differences in optima correlated significantly with the average nutrient affinity of the species recorded in that region $(\mathrm{cor}=0.82, \mathrm{t}=3.539, \mathrm{df}=6, P=0.012$ ), with relatively lower roadside optima in regions with on average lower nitrogen affinities and vice versa.

Table 3 shows that sufficient regional data to get a significant model was available for both parameters in three regions (MT, OR, SW) and for amplitude in an additional set of two regions (AU and CLS). For CLS, origin was not significant, and the model only holds for non-native species. In SW, model results only apply to native species. Patterns for species that occured in at least two different regions were consistent for changes in range amplitudes ( $\operatorname{cor}=0.21, \mathrm{t}=2.033 \mathrm{df}=93, P=0.045)$, but not for range optima (cor $=-0.021, \mathrm{t}=-0.202, \mathrm{df}=93, P=0.842)$. The observed changes in range amplitude in roadsides compared to the adjacent vegetation could be a statistical artefact of an increase in the presence of the species in the roadsides. There was indeed a correlation between the difference in the amount of occurrences and the difference in amplitude between roadsides and adjacent plots (cor = $0.465, \mathrm{df}=508, \mathrm{t}=11.830, P<0.001)$, but not with the differences in range averages $(\mathrm{cor}=-0.016, \mathrm{df}$ $=508, \mathrm{t}=-0.362, P=0.718)$.

\section{Discussion}

\section{Non-native species}

Elevational range amplitudes of non-native plant species were on average broader in the roadsides than in the adjacent vegetation. Roadsides have often been shown to serve as a vector for non-native species to higher elevations, as they combine the necessary propagule dispersal through human traffic with 
locally improved abiotic conditions (Seipel et al. 2012, Barros and Pickering 2014, Lembrechts et al. 2014). Concerning the latter, non-native species occurrence in roadsides has for example been linked to the occurrence of road edge habitats with increased resource availability (Paiaro et al. 2011, Pollnac et al. 2012), and in our survey, non-native species with high nitrogen affinity indeed showed the largest increases in elevational optima in roadsides. The higher nutrient levels that are commonly recorded in roadsides could thus serve as a trigger for the successful establishment of non-native species in roadsides at higher elevations (Davis et al. 2000, Godefroid and Koedam 2004, Müllerová et al. 2011, Paiaro et al. 2011). These higher nutrient levels might especially be important facilitators of non-native species establishment at the highest elevations, as alpine environments are often nutrient-limited. Suprisingly, all observed non-native species had moderate to high temperature affinities (Landolt values of three or more), indicating that adaptation to lowland climatic condition is a premise for nonnative species to invade mountain ecosystems (Alexander et al. 2011). Direct transportation of coldadapted species from one mountain region to the other is thus apparently until now a minor process, although it remains a high risk as a driver of future mountain invasions (Pauchard et al. 2009).

The expansion of non-natives, especially lowland species with high nitrogen-affinity, along roadsides, strengthens conclusions from other research that the distribution of non-native species in mountains is currently more determined by the presence of suitable growing conditions (e.g. less competition and more nutrients in roadsides) and the availability of propagules (facilitated by roads) than by climatic or elevational limitations (Marini et al. 2012). Their roadside ranges indeed indicate that they can occur at higher elevations in the mountains than they are currently found in the adjacent natural vegetation. Our data hint that although all non-native species have broader ranges in the roadsides than in the adjacent plots, non-native species better adapted to mountain climates (lower Landolt temperature values) show the largest range expansion (Pauchard et al. 2009, Lembrechts et al. 2014). It should be noted, though, that the observed increases in range amplitudes could partially be a statistical artefact of a higher occurrence of a species in the roadside. The directionality of the observed shifts however indicates that the increased amplitudes are more than just directed by chance.

Regional patterns for non-native species in our dataset were mostly consistent with the global results. Non-native species for example showed broader roadside range amplitudes in all of the regions (although only significantly in those regions were data availability was sufficient), which strengthens the conclusion that a broader elevational range for non-native species in roadsides is a global pattern

'This article is protected by copyright. All rights reserved.' 
(Seipel et al. 2012). The absence of non-native species with more than 10 occurrences in Old World regions (NO and SW) is probably due to the Eurasian origin of many mountain invaders (Seipel et al. 2012). The two regions (MT, OR) that showed a higher optimum for non-native species in the roadsides than the adjacent vegetation were located in a temperate climate, while the one negative optimum difference occurred in a Mediterranean climate (AU). In the latter system, drought and heat which are amplified in roadsides - might actually restrict invasion in lowlands more than at intermediate elevations, which could explain the reversed pattern.

\section{Native species}

Native species also generally had broader range amplitudes in roadsides than in the adjacent vegetation (Table 3), although the difference was less pronounced than for non-native species. We could, however, not observe any general pattern for range changes, due to the presence of three species groups with opposite trends. Indeed, lowland species had an upward increase in their upper edge in roadsides, while the lower range edges of high elevation species reached to lower elevations, with both patterns leveling each other out in the intermediate group. Native species with high nitrogen affinity, but low temperature affinity, also showed higher range optima in the roadside, confirming previous research (Godefroid and Koedam 2004, Müllerová et al. 2011, Lembrechts et al. 2014), while native species with low nitrogen affinity had relatively lower roadside range optima, although these conclusions are only based on $48 \%$ of the observed native species.

Trends in the direction of the optimum for native species varied between regions, although differences were negative in all significant cases (Fig. 1B, Table 2). The final pattern depended on the average nutrient affinity of the species in the regional dataset. Regions with native species with lower nitrogen affinity showed lower optima in roadsides than in the natural vegetation, and vice versa. This could either be an artefact of the limited availability of Landolt values for non-European regions or link to varying patterns of soil fertility between regions.

\section{General effects of roads on native and non-native plant ranges}

Patterns were surprisingly similar between lowland native and lowland non-native species. Roads thus serve as a vector for (both native and non-native) lowland plants and facilitate their invasion towards higher elevations (Alexander et al. 2011, Taylor et al. 2012). That these patterns were not limited to non-native species might indicate an additional use of roads as pathways for native species expanding their ranges into mountains under climate change. This relates to the observed upward spread of 
lowland species in mountains as so-called local invaders in a warming climate (Lenoir et al. 2010). Roads might promote the spread of such species triggered by climate change by providing an easy pathway to reach elevations above their current climatic limits, from where they can start colonising the adjacent natural vegetation. This process could accelerate climate change induced range shifts as roads weaken barriers, such as biotic competition and low nutrient levels, experienced by upward moving species (Walther et al. 2005, Lenoir et al. 2009, Lenoir et al. 2010, Zhu et al. 2012). Roadside processes thus could increase the discrepancy in the upward moving speed of different species under climate change, by faciliting the upward movement of fast-growing species with a quick generation turn-over even more than already observed (Lenoir et al. 2008).

High-elevation species surprisingly showed an opposite trend, with lower reaching lower edges in roadsides than in the adjacent vegetation. Our results suggest that those species might benefit from the altered abiotic conditions and the competitive release in roadsides to expand their ranges towards lower elevations, against the general uphill movement driven by climate change (Forman et al. 2003, Lenoir et al. 2010, Lembrechts et al. 2014). As the lower realised range margin of alpine species is often not defined by abiotic conditions but by their inability to compete with faster growing lowland species (Lenoir et al. 2010, le Roux et al. 2012), this downward shift along disturbed roadsides areas should not come as a surprise. Competitive release has earlier been suggested as a driver of similar unexpected downward range shifts of plants as climate warms (Vetaas 2002, Lenoir et al. 2010). Our results imply that roadsides could serve as corridors for native species movements, bridging lowland gaps between separate populations of certain mountain species.

It has often been observed that mountain species have lower nitrogen affinity (Körner 2003), and in our results lower optima in roadsides are similarly linked to lower nitrogen affinity. We thus observe two contrasting nutrient-related patterns, with both species with low and high nitrogen affinity showing broader ranges in the roadsides than in the adjacent vegetation. Species with low nitrogen-affinity are not restricted to nutrient-poor environments, but microvariation in roadside habitats has also been proven to result in a variety of abiotic conditions (e.g. edges versus fill slopes) (Paiaro et al. 2011), suggesting that highland species with low nitrogen affinity might use other parts of the roadside than lowland species. Fill slopes for example have high resource availability and facilitate fast-growing lowland species through resource enrichment, while rocky roadside substrates have scarce soils and unstable hydrological and thermal conditions and thus favour the presence of stress-tolerant species. 
This implies that roadsides host a large variety of plant species on a small surface area, increasing their vulnerability for instability.

Several species occurred in more than one region and differences in their range amplitudes were positively correlated between regions, implying that species ranges would in general either be positively or negatively affected by roadsides, regardless of the region. Directions of changes in optima did not show a significant correlation, indicating that there was still a significant portion of regional variation in the effects of roads at species level, despite the general trends and the consistency in their affinity for roadsides or not. Possible explanations for these differences could be residence time of nonnative species, regional climatic differences or region- or road-specific variation such as levels of roadside disturbance.

It is clear from these results that the elevational range of a wide variety of plant species differs between roadsides and the adjacent vegetation. Surprisingly, these range differences are not limited to the welldocumented expansion of non-native species along mountain roads, but also include native species, which, depending on the species, show either higher or lower range optima in roadsides. The consistent trend towards broader range amplitudes in roadsides for both native and non-native plant species might find its main explanation in the reoccurring disturbance events in roadsides that alter resource availability and biotic interactions, which have a known positive impact on both ruderal native and non-native species, as well as stress-tolerant mountain species (le Roux et al. 2012). Several other factors probably play a role, like the presence of vehicles that can serve as vectors for species movement up and down mountain roads, thereby acilitating invasion at other elevations (Von der Lippe and Kowarik 2007). Small-scale variation in abiotic conditions in close proximity to roads could play an additional role in creating different niche spaces (Paiaro et al. 2011).

\section{Implications}

It is currently not possible to predict the stability of the range changes observed in roadsides because source-sink dynamics might be more important drivers of the observed changes in elevational niches on a long temporal scale. Thanks to the improved mobility in roadsides, species might indeed quickly establish roadside populations at high or low elevations which are potentially outside of their longerterm elevational niche. It is also important to keep in mind that roadside environments are highly unstable and comprise only a small part of the mountain area, which means that a stable source population might remain necessary to maintain the observed role as a refuge for these species outside 
their current range in the natural vegetation. Our results however suggest that roads play a more important role as drivers of range changes than previously assumed. They likely facilitate climateinduced upward range shifts for both native and non-native plant species and they could serve as corridors to facilitate exchange of alpine species between adjacent high-elevation mountain sites and slow down the observed upward retreat of the trailing edge of these species under climate change (Lenoir et al. 2010).

We conclude that roadsides indeed serve as corridors for species movements and as such trigger range dynamics of species (whether native or non-native) into new climatic zones (Paiaro et al. 2011). Lowland species with high nutrient affinity profit the most from these altered conditions and patterns are strongest for, but not limited to, non-native species. Roadsides can hence serve as an important early detection system where shifts in species ranges will become visible first. These monitoring systems in roadsides might however be sensitive to short-term population fluctuations, but are nevertheless useful to finetune existing species distribution models. By adding roadsides as an extra factor, the description of true realised elevational niches will be more accurate and predictions of range changes under future climate conditions will be more reliable.

'This article is protected by copyright. All rights reserved.' 


\section{Acknowledgements}

We express our gratitude to the data collectors in the different MIREN-regions and acknowledge the input from two anonymous reviewers. We gratefully acknowledge the grants from the Research Foundation - Flanders (FWO) to J.J. Lembrechts and the support from the Swedish Research Council (VR 2012-6252) to A. Milbau, A. Pauchard and M. Nuñez.

\section{Citations}

Alexander, J. M. et al. 2011. Assembly of nonnative floras along elevational gradients explained by directional ecological filtering. - P Natl Acad Sci USA 108: 656-661.

Ansong, M. and Pickering, C. 2013. Are weeds hitchhiking a ride on your car? A systematic review of seed dispersal on cars. - Plos One 8:

Avon, C. et al. 2010. Does the effect of forest roads extend a few meters or more into the adjacent forest? A study on understory plant diversity in managed oak stands. - Forest Ecol Manag 259: 1546-1555.

Barros, A. and Pickering, C. M. 2014. Non-native plant invasion in relation to tourism use of Aconcagua Park, Argentina, the highest protected area in the Southern Hemisphere. - Mt Res Dev 34: 13-26.

Bates, D. et al. 2013. Ime4: Linear mixed-effects models using Eigen and S4.

Becker, T. et al. 2005. Altitudinal distribution of alien plant species in the Swiss Alps. - Perspect Plant Ecol 7: 173-183.

Bergès, L. et al. 2013. Influence of forest road, road-surfacing material and stand age on floristic diversity and composition in a nutrient-poor environment. - Appl Veg Sci 16: 470-479.

Bertrand, R. et al. 2011. Changes in plant community composition lag behind climate warming in lowland forests. - Nature 479: 517-520.

Bolnick, D. I. et al. 2010. Ecological release from interspecific competition leads to decoupled changes in population and individual niche width. - Proceedings of the Royal Society B-Biological Sciences 277: 1789-1797.

Corlett, R. T. and Westcott, D. A. 2013. Will plant movements keep up with climate change? - Trends Ecol Evol 28: 482-488.

Davis, M. A. et al. 2000. Fluctuating resources in plant communities: a general theory of invasibility. Journal of Ecology 88: 528-534.

Delgado, J. D. et al. 2007. Edge effects of roads on temperature, light, canopy cover, and canopy height in laurel and pine forests (Tenerife, Canary Islands). — Landscape Urban Plan 81: 328340.

Felde, V. A. et al. 2012. Upward shift in elevational plant species ranges in Sikkilsdalen, central Norway. - Ecography 35: 922-932.

Forman, R. T. T. and Alexander, L. E. 1998. Roads and their major ecological effects. - Annu Rev Ecol Syst 29: 207-231.

Forman, R. T. T. et al. 2003. Road Ecology. Science and solutions. - Island Press.

Gelbard, J. L. and Belnap, J. 2003. Roads as conduits for exotic plant invasions in a semiarid landscape. - Conserv Biol 17: 420-432.

Godefroid, S. and Koedam, N. 2004. The impact of forest paths upon adjacent vegetation: effects of the path surfacing material on the species composition and soil compaction. - Biol Conserv 119: 405-419.

Grabherr, G. et al. 1994. Climate effects on mountain plants. - Nature 369: 448-448.

'This article is protected by copyright. All rights reserved.' 
Güsewell, S. and Klötzli, F. 2012. Local plant species replace initially sown species on roadsides in the Swiss National Park. - Eco Mont-Journal on Protected Mountain Areas Research 4: 23-33.

Haider, S. et al. 2010. The role of bioclimatic origin, residence time and habitat context in shaping non-native plant distributions along an altitudinal gradient. - Biol Invasions 12: 4003-4018.

Haider, S. et al. 2011. Elevational distribution limits of non-native species: combining observational and experimental evidence. - Plant Ecology \& Diversity 4: 363-371.

Johnston, F. M. and Johnston, S. W. 2004. Impacts of road disturbance on soil properties and on exotic plant occurrence in subalpine areas of the Australian Alps. - Arct Antarct Alp Res 36: 201-207.

Jump, A. S. et al. 2012. Rapid altitudinal migration of mountain plants in Taiwan and its implications for high altitude biodiversity. - Ecography 35: 204-210.

Juvik, J. O. et al. 2011. "The upper limits of vegetation on Mauna Loa, Hawaii": a 50th-anniversary reassessment. - Ecology 92: 518-525.

Körner, C. 2003. Alpine plant life: functional plant ecology of high mountain ecosystems. - Springer.

Kueffer, C. et al. 2014. The Mountain Invasion Research Network (MIREN) linking local and global scales for addressing an ecological consequence of global change. - Gaia-Ecological Perspectives for Science and Society 23: 263-265.

Landolt, E., Bäumler, B., Erhardt, A., Hegg, O., Klötzli, F., Lämmler, W., Nobis, M., Rudmann-Maurer, F., Schweinsgruber, F.H., Theurillat, J.P., et al. 2010. Flora indicativa. - Haupt.

le Roux, P. C. et al. 2012. Biotic interactions affect the elevational ranges of high-latitude plant species. - Ecography 35: 1048-1056.

Lembrechts, J. J. et al. 2014. Alien roadside species more easily invade alpine than lowland plant communities in a subarctic mountain ecosystem. - Plos One 9(2):

Lenoir, J. et al. 2008. A significant upward shift in plant species optimum elevation during the 20th century. - Science 320: 1768-1771.

Lenoir, J. et al. 2009. Differences between tree species seedling and adult altitudinal distribution in mountain forests during the recent warm period (1986-2006). - Ecography 32: 765-777.

Lenoir, J. et al. 2010. Going against the flow: potential mechanisms for unexpected downslope range shifts in a warming climate. - Ecography 33: 295-303.

Leung, G. P. C. et al. 2009. Exotic plant invasion in the highly degraded upland landscape of Hong Kong, China. - Biodivers Conserv 18: 191-202.

Marini, L. et al. 2012. Alien and native plant life-forms respond differently to human and climate pressures. - Global Ecol Biogeogr 21: 534-544.

Mazerolle, M. J. 2015. AICcmodavg: Model selection and multimodel inference based on (Q)AIC(c).

McDougall, K. L. et al. 2011. Alien flora of mountains: global comparisons for the development of local preventive measures against plant invasions. - Divers Distrib 17: 103-111.

MIREN 2005. MIREN: The Mountain Invasion Research Network.

Müllerová, J. et al. 2011. The impacts of road and walking trails upon adjacent vegetation: Effects of road building materials on species composition in a nutrient poor environment. - Sci Total Environ 409: 3839-3849.

Paiaro, V. et al. 2011. Altitudinal distribution of native and alien plant species in roadside communities from central Argentina. - Austral Ecol 36: 176-184.

Pauchard, A. et al. 2009. Ain't no mountain high enough: plant invasions reaching new elevations. Front Ecol Environ 7: 479-486.

Pauli, H. et al. 2007. Signals of range expansions and contractions of vascular plants in the high Alps: observations (1994-2004) at the GLORIA*master site Schrankogel, Tyrol, Austria. - Global Change Biol 13: 147-156.

Pinheiro, J. et al. 2013. nlme: linear and nonlinear mixed effects models.

Pollnac, F. et al. 2012. Plant invasion at landscape and local scales along roadways in the mountainous region of the Greater Yellowstone Ecosystem. - Biol Invasions 14: 1753-1763.

Pollnac, F. W. and Rew, L. J. 2014. Life after establishment: factors structuring the success of a mountain invader away from disturbed roadsides. - Biol Invasions 16: 1689-1698.

Pyšek, P. et al. 2011. Colonization of high altitudes by alien plants over the last two centuries. $-P$ Natl Acad Sci USA 108: 439-440.

R Core Team 2013. R: a language and environment for statistical computing. - In: R Foundation for Statistical Computing, V., Austria. (ed).

'This article is protected by copyright. All rights reserved.' 
Seipel, T. et al. 2012. Processes at multiple scales affect richness and similarity of non-native plant species in mountains around the world. - Global Ecol Biogeogr 21: 236-246.

Seipel, T. et al. 2015. Performance of the herb Verbascum thapsus along environmental gradients in its native and non-native ranges. - J Biogeogr 42: 132-143.

Taylor, K. et al. 2012. Human-mediated long-distance dispersal: an empirical evaluation of seed dispersal by vehicles. - Divers Distrib 18: 942-951.

ter Braak, C. F. and Looman, C. N. 1986. Weighted averaging, logistic regression and the Gaussian response model. - Vegetatio 65: 3-11.

Vetaas, O. R. 2002. Realized and potential climate niches: a comparison of four Rhododendron tree species. - J Biogeogr 29: 545-554.

Von der Lippe, M. and Kowarik, I. 2007. Long-distance dispersal of plants by vehicles as a driver of plant invasions. - Conserv Biol 21: 986-996.

Walther, G. R. et al. 2002. Ecological responses to recent climate change. - Nature 416: 389-395.

Walther, G. R. et al. 2005. Trends in the upward shift of alpine plants. - J Veg Sci 16: 541-548.

Zhu, K. et al. 2012. Failure to migrate: lack of tree range expansion in response to climate change. Global Change Biol 18: 1042-1052.

'This article is protected by copyright. All rights reserved.' 


\section{Table Legends}

Table 1. Characteristics of the eight regions, including the coordinates, the number of roads sampled, the range from the minimum to the maximum elevation of the sampling plots, and the total number of non-native and native vascular plants with more than five occurrences in both roadside and adjacent plots recorded per region, with the number of species with known Landolt values in parentheses.

\begin{tabular}{|c|c|c|c|c|c|}
\hline Region & Coordinates & Roads & $\begin{array}{l}\text { Elevational } \\
\text { range (m a.s.l.) }\end{array}$ & $\begin{array}{l}\text { Non-native } \\
\text { species }\end{array}$ & Native species \\
\hline Argentina (AR) & $\begin{array}{l}41^{\circ} 10^{\prime} \mathrm{S} 071^{\circ} 55^{\prime} \\
\mathrm{W}\end{array}$ & 3 & $857-1678$ & $6(5)$ & $32(0)$ \\
\hline Australia (AU) & $36^{\circ} 06^{\prime} \mathrm{S} 148^{\circ} 18^{\prime} \mathrm{E}$ & 3 & $410-2125$ & $12(11)$ & $47(3)$ \\
\hline Central Chile (CLC) & $\begin{array}{l}33^{\circ} 54^{\prime} \mathrm{S} 070^{\circ} 18^{\prime} \\
\text { W }\end{array}$ & 1 & $1895-3585$ & $2(2)$ & $5(1)$ \\
\hline Montana, USA (MT) & $\begin{array}{l}44^{\circ} 48^{\prime} \mathrm{N} 110^{\circ} 24^{\prime} \\
\text { W }\end{array}$ & 3 & $1803-3307$ & $7(7)$ & $70(12)$ \\
\hline Norway (NO) & $68^{\circ} 19^{\prime} \mathrm{N} 017^{\circ} 80^{\prime} \mathrm{E}$ & 3 & $13-697$ & $0(0)$ & $47(34)$ \\
\hline Oregon, USA (OR) & $\begin{array}{l}45^{\circ} 18^{\prime} \mathrm{N} 117^{\circ} 48^{\prime} \\
\text { W }\end{array}$ & 3 & $902-2265$ & $25(23)$ & $121(19)$ \\
\hline $\begin{array}{l}\text { Southern Chile } \\
\text { (CLS) }\end{array}$ & $\begin{array}{l}36^{\circ} 58^{\prime} \mathrm{S} 071^{\circ} 24^{\prime} \\
\text { W }\end{array}$ & 3 & $274-1668$ & $19(18)$ & $16(0)$ \\
\hline Switzerland (SW) & $46^{\circ} 12^{\prime} \mathrm{N} 007^{\circ} 12^{\prime} \mathrm{E}$ & 4 & 411-1802 & $0(0)$ & $101(97)$ \\
\hline
\end{tabular}

'This article is protected by copyright. All rights reserved.' 
Table 2. Estimates, P-values and degrees of freedom for general (all, bold) and regional linear mixed null models for range optima (left) and amplitudes (right), for non-native (top) and native (bottom) species. Significant P-values are marked with an asterix $\left(^{*}\right)$ and P-values between 0.05 and 0.10 with a period (.). Data from dataset A1.

\begin{tabular}{|c|c|c|c|c|c|c|}
\hline \multirow[t]{2}{*}{$\underline{\text { Non-natives }}$} & \multicolumn{3}{|c|}{ Optimum 1 } & \multicolumn{3}{|c|}{ Amplitude $\sim 1$} \\
\hline & Estimate & P-value & df & Estimate & P-value & $\mathrm{df}$ \\
\hline All & 38.9 & 0.326 & 65 & 191.5 & $<0.001 *$ & 65 \\
\hline Argentina & -0.6 & 0.986 & 5 & 31.2 & 0.560 & 5 \\
\hline Australia & -99.8 & $0.039 *$ & 11 & 304.6 & 0.074 . & 11 \\
\hline Central Chile & 113 & 0.408 & 1 & 193.5 & 0.500 & 1 \\
\hline Montana & 142.0 & $<0.001 *$ & 6 & 213 & 0.148 & 6 \\
\hline Norway & - & - & - & - & - & - \\
\hline Oregon & 110.9 & $<0.001 *$ & 24 & 191.5 & $0.005 * *$ & 24 \\
\hline Southern Chile & -8.6 & 0.705 & 18 & 162.7 & $0.010 *$ & 18 \\
\hline Switzerland & - & - & - & - & - & - \\
\hline \multicolumn{7}{|l|}{ Natives } \\
\hline All & -14.4 & 0.212 & 431 & -14.3 & 0.670 & 431 \\
\hline Argentina & -29.4 & 0.187 & 31 & $\begin{array}{l}-51.8 \\
\end{array}$ & $0.021 *$ & 31 \\
\hline Australia & -97.3 & $0.010 *$ & 46 & -136.7 & $0.003 *$ & 46 \\
\hline Central Chile & 54.4 & 0.362 & 4 & -136.4 & 0.376 & 4 \\
\hline Montana & 23.8 & 0.061 . & 69 & -28.7 & 0.380 & 69 \\
\hline Norway & -29.8 & $0.002 *$ & 46 & 0.872 & 0.970 & 46 \\
\hline Oregon & 14.2 & 0.138 & 120 & -8.7 & 0.678 & 120 \\
\hline Southern Chile & -32.3 & 0.126 & 15 & 13.94 & 0.789 & 15 \\
\hline Switzerland & -40.7 & $0.003 *$ & 100 & 153.6 & $<0.001 *$ & 100 \\
\hline
\end{tabular}


Table 3. Fstimates and P-values for general (all, bold) and regional linear mixed models for range optima (top) and amplitudes (bottom) for species origin $\left(\mathrm{OR}_{\mathrm{N}}=\right.$

2 native, incer pt is for on-native), nitrogen ( $\mathrm{N}$ ) and temperature ( $\mathrm{T}$ ) affinity and relevant two-way interactions. Only estimates and interactions shown for models 3 with the best It. Data Irom dataset A1.

\begin{tabular}{|c|c|c|c|c|c|c|c|c|c|c|c|c|}
\hline Optimum & (Int) & $\mathrm{P}$ & $\mathrm{OR}_{\mathrm{N}}$ & $\mathrm{P}$ & $\mathrm{T}$ & $\mathrm{P}$ & $\mathrm{N}$ & $\mathrm{P}$ & $\mathrm{OR}_{\mathrm{N}} * \mathrm{~T}$ & $\mathrm{P}$ & $\mathrm{T}^{*} \mathrm{~N}$ & $\mathrm{P}$ \\
\hline All & -204.7 & 0.038 & 177.0 & 0.079 & 42.9 & 0.062 & 25.8 & 0.005 & -65.4 & 0.014 & - & - \\
\hline Argentina & & - & - & - & - & - & - & - & - & - & - & - \\
\hline Australia & - & - & - & - & - & - & - & - & - & - & - & - \\
\hline Central Chile & & - & - & - & - & - & - & - & - & - & - & - \\
\hline Montana & 142.0 & $<0.001$ & -118.3 & 0.004 & - & - & - & - & - & - & - & - \\
\hline Norway & & - & - & - & - & - & - & - & - & - & - & - \\
\hline Oregon & & $<0.001$ & -96.7 & $<0.001$ & - & - & - & - & - & - & - & - \\
\hline Southern C & & - & - & - & - & - & - & - & - & - & - & - \\
\hline Switzerland & 4 & $<0.001$ & - & - & - & - & 50.1 & 0.001 & - & - & - & - \\
\hline \multicolumn{13}{|l|}{$\underline{\text { Amplitude }}$} \\
\hline All & & 0.007 & -659.2 & 0.006 & -89.6 & 0.103 & - & - & 108.7 & 0.086 & - & - \\
\hline Argentina & & - & - & - & - & - & - & - & - & - & - & - \\
\hline Australia & & 0.013 & -2084.7 & 0.022 & -375.7 & 0.038 & - & - & 367.6 & 0.099 & - & - \\
\hline Central Chile & & - & - & - & - & - & - & - & - & - & - & - \\
\hline Montana & 0 & 0.046 & -241.7 & 0.031 & - & - & - & - & - & - & - & - \\
\hline
\end{tabular}




\begin{tabular}{|c|c|c|c|c|c|c|c|c|c|c|c|c|}
\hline Norway & - & - & - & - & - & - & - & - & - & - & - & - \\
\hline Oregon & 195 & $<0.001$ & -200.1 & $<0.001$ & - & - & - & - & - & - & - & - \\
\hline Southern $\mathrm{Cn}$ & $-4 / 73.5$ & 0.045 & - & - & 1150.2 & 0.044 & 1648.4 & 0.031 & - & - & -387.3 & 0.037 \\
\hline Switzerland & -165.9 & 0.308 & - & - & 99.7 & 0.048 & - & - & - & - & - & - \\
\hline
\end{tabular}

4

5
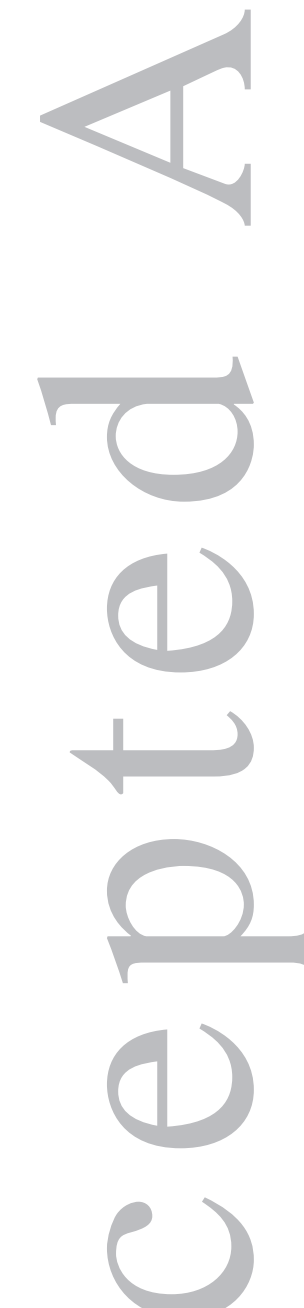

'This article is protected by copyright. All rights reserved.' 


\section{Figure Legends}

Figure 1. Differences (in elevational meters) in range optima (x) and amplitudes (y) between roadsides and adjacent plots for dataset A1 (top) and A2 (bottom), and for the global dataset (left) and the regional subsets (right). Species- and region-specific values are marked with small dots. In A and C, non-native species are marked with orange squares, native species with blue circles, in B and D they are left black for clarity. Overall average optima and amplitude values for natives and non-natives are marked respectively with a large blue dot and an orange square $(\mathrm{A}, \mathrm{C})$ (only the range amplitude for non-native species from dataset A1 (Fig. 1A) differed significantly from zero). Regional averages $(\mathrm{B}, \mathrm{D})$ are marked with numbers, with larger fontsize for significant results. $1=\mathrm{AR}$, Argentina, $2=\mathrm{AU}$, Australia, 3 = SW, Switzerland, 4 = CLC, Central Chile, 5 = CLS, Southern Chile, $6=$ MT, Montana, 7 $=$ OR, Oregon, $8=$ NO, Norway. 

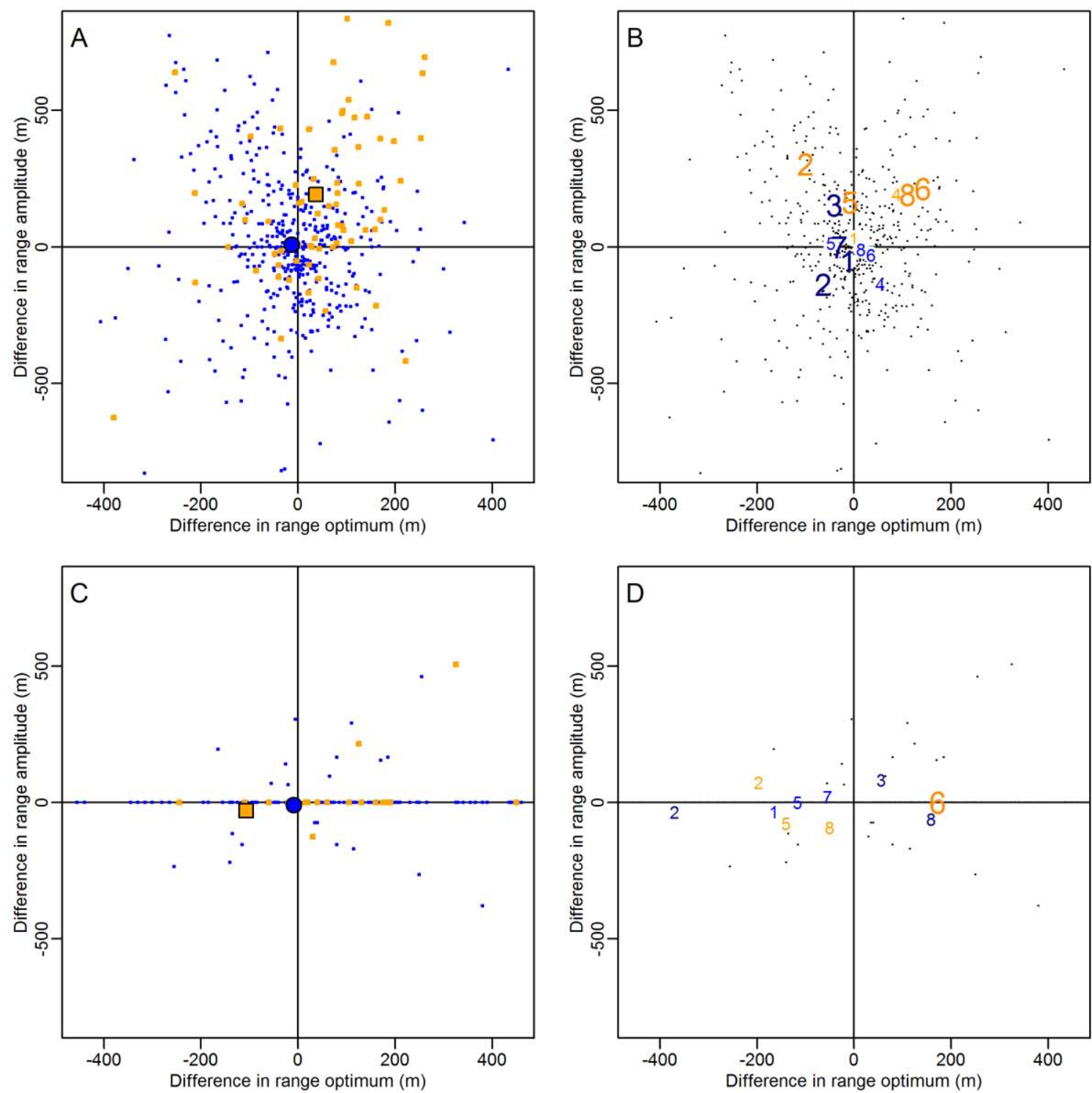

'This article is protected by copyright. All rights reserved.' 
Figure 2. Top: Average elevational differences in edge (for species with an optimum below or above the sampled road fragment) or optimum (for species with their optimum along the road fragment) (+- 1 SD) between roadsides and adjacent plots for non-native (A) and native species (B) seperately. Bottom: Example of a species with its optimum along the sampled road fragment, showing a downward shift (C, Pinguicula vulgaris, Norway) and one with its optimum below the road, with a higher range end in the roadside compared to the adjacent plots ( $\mathrm{D}$, Tragopogon dubius, Montana). Red line = roadside, black line $=$ natural vegetation, black arrow connects optimum $(C)$ or edge $(D)$ in the natural vegetation with the corresponding value in the roadside. Data from dataset A2 and A3.
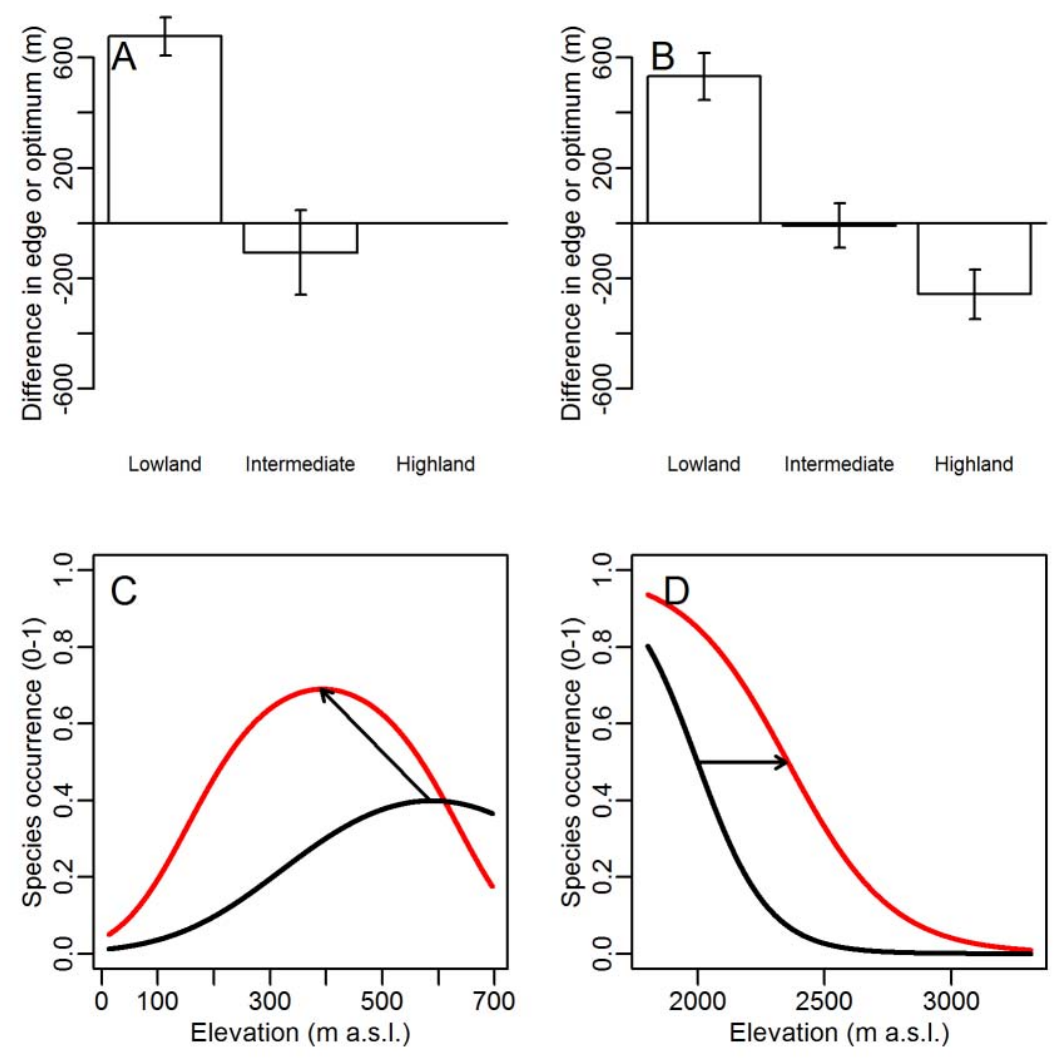

'This article is protected by copyright. All rights reserved.' 
Figure 3. Differences (in $\mathrm{m}$ ) in elevational optima between roadside and adjacent plots for non-native $(\mathrm{A}, \mathrm{C})$ and native $(\mathrm{B}, \mathrm{D})$ species based on data from dataset $\mathrm{A} 1(\mathrm{~A}, \mathrm{~B})$ and dataset $\mathrm{A} 2$ (C, D), as a function of nitrogen (x) and temperature (y) affinity. Graphs based on the general LMMs with the best fit $($ see Table 3 ). Red = positive values and thus higher optima in roadsides than in the natural vegetation, blue $=$ negative values and thus lower optima, white $=$ no clear trend.
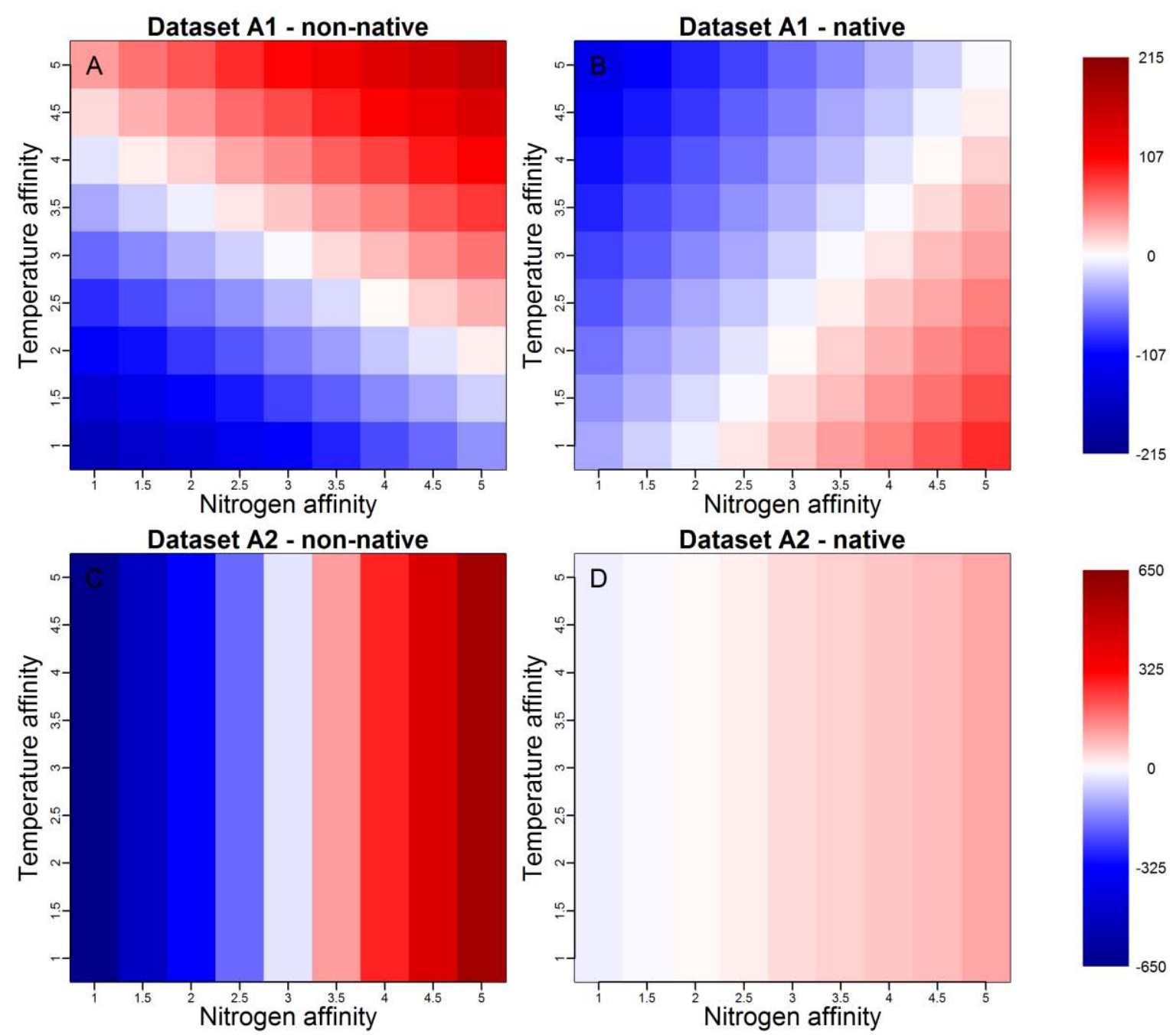

'This article is protected by copyright. All rights reserved.' 